ISSN: 2091-0657 (Print); 2091-0673 (Online)

Open Access

\title{
Experience of one hundred cases of ASD closure
}

\section{Jayapal Reddy ${ }^{1}$, Bijay $\mathrm{Sah}^{2}$}

${ }^{1}$ Professor and Head of Department, ${ }^{2} \mathrm{MCh}$ Resident, Department of CTVS, College of Medical Sciences, Teaching Hospital, Bharatpur, Nepal

\begin{tabular}{l}
\hline Correspondence \\
Dr. D. Jayapal Reddy, \\
Department of CTVS, College \\
of Medical Sciences, \\
Teaching Hospital, Bharatpur, \\
Nepal. \\
Email: \\
drdjayapalreddy@gmail.com \\
DOI: http://dx.doi.org/10.3126/ \\
jcmsn.v11i4.14318
\end{tabular}

DOI: http://dx.doi
jcmsn.v11i4.14318

\begin{abstract}
Background \& Objectives: Atrial Septal Defect is a common congenital heart disease and surgical closure is the treatment of choice in many cases. This article presents the diagnostic criteria, surgical technique and postoperative management of hundred consecutive patients operated by a single surgeon at single centre. Materials and methods: One hundred (100) patients having atrial septal defect (ASD) underwent surgery at Osmania General Hospital, OMC, Hyderabad between January 1990 and October 1998. Sixty eight percentages $(68 \%)$ of the patients were females and $32 \%$ of the patients were male. Fifty nine percentages $(59 \%)$ of patients were in the age group of 11-30 yrs. Majority of the patients (70\%) were symptomatic and were in NYHA class II. 'O' Rh-positive blood group was found in $35 \%$ of patients. Associated cardiac lesions were present in $28 \%$ of cases. One case each of Cortriatrium, Lutembacher's syndrome and Holt-Oram syndrome were present in this series. Eighty nine percentages $(89 \%)$ were moderate sized defects repaired by direct closure where as rest of $11 \%$ needed patch repair. Cold crystalloid cardioplegia with moderate hypothermia $\left(28^{\circ} \mathrm{C}\right)$ was employed in 83 cases, ventricular fibrillation at normothermia in 5 cases and normothermic warm blood cardioplegia with continuous perfusion of coronary arteries in 12 patients. Results: Total duration of cardiopulmonary bypass ranged from 21 minutes to 100 minutes (mean duration 54.4 minutes) and aortic cross clamp time ranged from 10 minutes to 68 minutes (mean duration 22.9 minutes). Blood transfusion requirement ranged from 1 unit to 10 units (mean 3.1 units). There was no hospital death. Postoperative complication rate was $15 \%$. Conclusion: Atrial septal defect closure is a safe, simple and effective operation with excellent long term results.

Key words: Atrial Septal Defect (ASD), Atrial Septal Defect Closure, Congenital Heart Disease (CHD)
\end{abstract}

Citation: Reddy DJ, Sah B. Experience of one hundred cases of ASD closure. JCMS Nepal. 2015;11 (4):9-13.

\section{INTRODUCTION}

Any opening in the atrial septum, other than a competent foramen ovale, is described as an atrial septal defect (ASD). Atrial septal defect occurs in one child per 1500 live births and account for 6-10 percent of all patients with cardiac diseases. It is the third most common form of congenital heart disorder presenting after childhood (bicuspid aortic valve and mitral valve prolapsed are first and second respectively). ${ }^{1-3}$

The interatrial septum of the heart is formed between the 27th and 37th days of intrauterine life. ${ }^{3,4}$ At the end of 4 th week, sickle-shaped septum primum divides common atrium into two halves leaving an opening in its lower part known as 'Ostium Primum'. As septum primum grows and closes ostium primum, its upper part breaks down to form 'ostium secondum, the septum secundum now grows down wards from roof of atrial chamber to overlap ostium secundum.

The right and left atria now communicate with each other through an oblique valvular opening called 'foramen ovale' which allow flow of blood from right to left atrium throughout fetal life. After birth, the foramen ovale is obliterated by an increase in left atrial pressure. In 25 to $30 \%$ of the people, foramen ovale may be patent after birth. ${ }^{4-6}$

Defects can occur anywhere in the interatrial septum. Bedford et all described different types of ASDs as follow: Fossa ovalis ASD (Ostium Secundum ASD)- the commonest ASD, posterior ASD, ostium primum ASD ( absence of the atrioventricular septum), coronary sinus ASD, sinus venosus (SVC type) ASD, low (IVC type) ASD and 
confluent ASD.

Gibbon in 1953 did first successful closure of ASD using extra corporeal circulation. Subsequently, Lewis successfully closed an atrial septal defect under direct vision by using hypothermia and inflow occlusion (Lewis and Taufi, 1953). ${ }^{6-8}$

One hundred patients diagnosed as having atrial septal defects clinically and echocardiography wise were operated in institute (Osmania General Hospital, OMC, Hyderabad) between January 1990 and October 1998 using cardiopulmonary bypass. This report reviewed and studied the patients retrospectively and presents the outcome.

\section{MATERIALS AND METHODS}

During the period from January, 1990 to October 1998, one hundred patients with atrial septal defects had undergone surgical repair/correction using cardiopulmonary bypass with a pump oxygenator at Osmania General Hospital, OMC, Hydrabad. The medical records were retrospectively analyzed and clinical features, surgical techniques along with associated mortality and morbidity conditions were studied. Sixty eight percentages $(68 \%)$ of the patients were females and $32(32 \%)$ were males (Fig 1). The patients varied in age from 6 years to 45 years (mean age 20.30 years) (Fig 2).

Seventy percentages $(70 \%)$ of patients were symptomatic while $30 \%$ were asymptomatic. The symptoms most frequently seen in children were slow growth and physical development often together with frequent lower respiratory tract infections $(16 \%)$ while in adults' exertional dyspnea (58\%), palpitation $(21 \%)$, chest pain $(26 \%)$, weakness and easy fatigability $(70 \%)$ were encountered. Majority $(88 \%)$ of the patients was in NYHA functional class-II (Table 1).

All patients were preoperatively diagnosed by echocardiography and cardiac catheterization was done only if the patients were symptomatic and had ECG changes or patients with severe pulmonary artery hypertension in doubtful diagnosis. Routine investigations, included complete haemogram, urine examination (CUE), liver function test, renal function tests, bleeding and clotting time, blood group \& typing, HIV, HbsAg and HCV, Chest xray, ECG and Echocargiography were done in all cases.

Surgical correction of atrial septal defects was indicated in all patients with symptoms related to atrial septal defect irrespective of the age. We also recommended surgical correction in all asymptomatic patients over the age of 4 or 5 years with a major defect (defined as having a $\mathrm{Qp} / \mathrm{Qs}$ ratio of $>2: 1$ ). Selection of patients with severe pulmonary hypertension associated with atrial septal defects was based on the presence of a net left to right shunt of $20-25 \%$ of the systemic flow and a systemic arterial oxygen saturation of $88 \%$ or greater.

Surgical approach was through median sternotomy in all patients. Moderate sized defects $(10-15 \mathrm{~mm} x$ $40-60 \mathrm{~mm}$ ) were repaired by direct closure satisfactorily with 3-0 prolene continuous sutures $/ 3$ -0 Ethibond continuous sutures in two layers. A prosthetic Dacron/ Pericardial patch was used in large defects, defects with thin margins that would not hold sutures well and in most of the cases with anomalous pulmonary venous connection.

Open mitral valvotomy combined with ASD closure was done in patient with Lutembacher's syndrome. Combined pulmonary valvotomy and ASD repair was done in patients with ASD and moderate to severe pulmonary stenosis (ASD closure was done first followed by pulmonary valvotomy through pulmonary arteriotomy).

Cardiopulmonary bypass was instituted using bubble/membrane oxygenator and Sarn's heart lung machine. Cold crystalloid cardioplegia with moderate hypothermia $\left(28\right.$ to $30{ }^{\circ} \mathrm{C}$ ), ventricular fibrillation at normothermia and normothermic warm blood cardioplegia with continuous perfusion of coronary arteries were employed for electromechanical arrest of the heart and

Table 1: Clinical Features

\begin{tabular}{|ll|}
\hline Clinical Features & No of patients (\%) \\
\hline Exertional dyspnoes & $58(58 \%)$ \\
\hline Chest pain & $26(26 \%)$ \\
\hline Palpitations & $21(21 \%)$ \\
\hline Easy fatigability & $70(70 \%)$ \\
\hline Respiratory tract infections & $16(16 \%)$ \\
\hline
\end{tabular}

Table 2: Associated lesions

\begin{tabular}{ll} 
Associated Lesions & No of patients (\%) \\
Rheumatic mitral stenosis & $1(1 \%)$ \\
$\begin{array}{l}\text { Partial anomalous pulmonary } \\
\text { venous drainage }\end{array}$ & $5(5 \%)$ \\
Pulmonary stenosis & $8(8 \%)$ \\
PDA & $1(1 \%)$ \\
Coarctation of aorta & $12(\%)$ \\
Mitral valve prolapsed & $12(12 \%)$ \\
Cortriatrium & $1(1 \%)$ \\
\hline
\end{tabular}


myocardial protection. Cold crystalloid cardioplegia was prepared by adding $30-40 \mathrm{mEq}$ of potassium chloride and 1000 units of heparin to 1 litre of Ringer lactate and kept overnight in refrigerator at $4^{\circ} \mathrm{C}$. Thousand milliliters $(1000 \mathrm{ml})$ of cold crystalloid cardioplegia was given as first dose and $600 \mathrm{ml}$ was given afterwards at $20 \mathrm{~min}$ interval. In this technique of normothermic warm blood cardioplegia with continuous perfusion of coronary arteries, cardioplegic concentrate (Inj. Potassium Chloride \& $25 \%$ Inj. Magnesium sulphate in 4:1 ratio) in $50 \mathrm{cc}$ syringe was infused into blood cardioplegia delivery line in two phases to induce electromechanical arrest and to maintain it.

After applying aortic cross clamp, cardioplegic concentrate was infused at the rate of $0.1 \mathrm{mEq}$ of KCL per $\mathrm{kg}$ body weight per minute until electromechanical arrest was achieved and delivered at a flow rate of 1-2 cc per $\mathrm{kg}$ body weight monitoring infusion pressure at below 100 $\mathrm{mmHg}$ ante-grade and below $40 \mathrm{mmHg}$ retrograde. The arrest was achieved within $60-180 \mathrm{sec}$. The maintenance dose was $0.01 \mathrm{mEq} / \mathrm{kg}$ body weight/ min. All patients were extubated in operation theatre. All patients were followed post operatively for variable periods ranging from 2 months to 8 years.

Eighty six percentages (86\%) patients had secundum type atrial septal defects, six patients had sinus venosus (SVC) type) of ASD and eight patients had low (IVC) type of ASD and five patients had PAPVC (anomalous drainage of right upper or lower lobe pulmonary veins into right atrium) with one patient among five having persistent left superior vena cava draining into coronary sinus (Fig 3).

Associated cardiac lesions were present in $28 \%$ of patients. Significant pulmonary stenosis requiring surgical intervention was present in eight patients. One patient had rheumatic mitral stenosis with ASD

Table 3: Post operative complications

\begin{tabular}{ll} 
Complications & No. of patients (\%) \\
\hline Wound infection & $5(5 \%)$ \\
\hline Junctional rhythm & $2(2 \%)$ \\
$\begin{array}{l}\text { Hemorrhage requiring } \\
\text { reoperation }\end{array}$ & $3(3 \%)$ \\
Wound dehiscence & $1(1 \%)$ \\
Right pneumothorax & $1(1 \%)$ \\
Right pleural effusion & $1(1 \%)$ \\
Atrial fibrillation & $1(1 \%)$ \\
Embolic stroke & $1(1 \%)$ \\
\hline
\end{tabular}

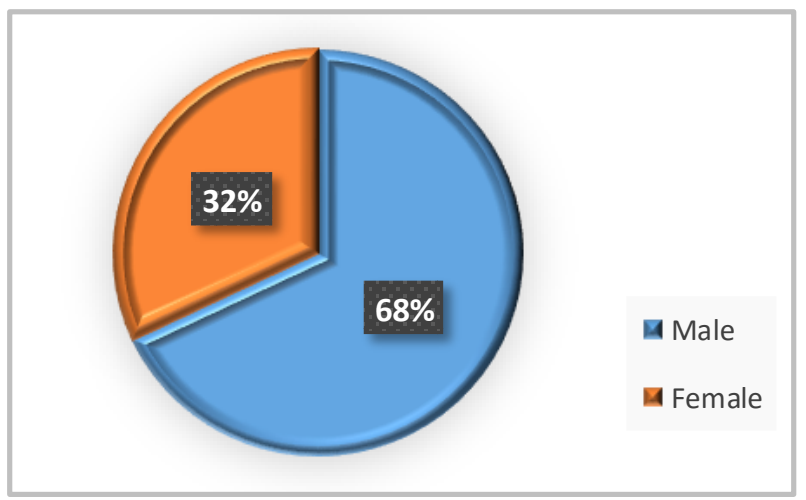

Fig 1: Male Female Percentages

(Lutembacher's syndrome). One patient had ASD with cortriatrium. One patient had PDA and one patient had coarctation of aorta which was detected postoperatively and balloon dilatation was done. Twelve patients had mitral valve prolapsed demonstrable in 2 dimensional echocardiography. One patient had Holt-Oram syndrome (ASD) with anomalies of the upper limbs (Table 2).

\section{RESULT}

All the patients recovered well after the surgery. Total duration of cardiopulmonary bypass period ranged from 21 minutes to 100 minutes (mean duration 54.4 minutes) and aortic cross clamp time ranged from 10 minutes to 68 minutes (mean duration 22.9 minutes). Blood transfusion requirement ranged from one to 10 units (mean 3.1 units).

The incidence of wound infection was 5\%. All three patients re-operated for hemorrhage did well in post operative period except for wound complications. One patient had sternal hematoma which was evacuated, one patient had bleeding from thymic vessels and left internal mammary artery which were controlled and other patient had diffuse oozing of blood which was managed. None of the patients

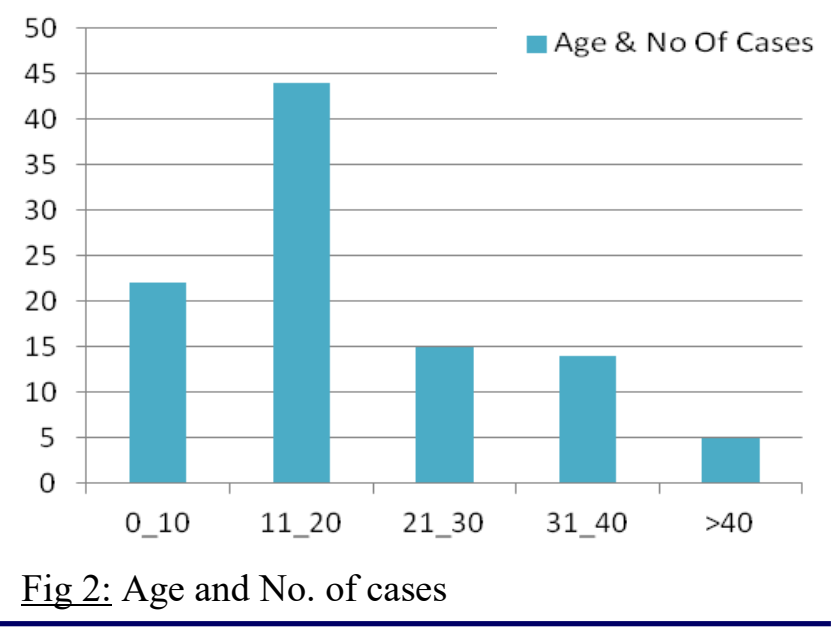


died of septic complications (Table 3 ).

Clinical, radiological and electrocardiographic changes after surgery were recorded. The patients not having significant pulmonary hypertension preoperatively showed a regression of virtually all symptoms present before operation. The diastolic murmurs disappeared and the systolic murmurs decreased in intensity or disappeared. The wide fixed type of splitting of the second sound had disappeared or changed so that it varied with the respiratory cycle.

The roentgenography heart size, pulmonary artery dilation and pulmonary vascularity decreased somewhat slowly. The electrocardiogram showed a shift of the mean QRS axis in the frontal plane toward the left (normal) and the right ventricular hypertrophy and strain have decreased. The right bundle branch block had not disappeared in most cases.

Majority of the patients were followed for varying periods from two months to eight years and long term results of atrial septal defect closure were excellent.

\section{DISCUSSION}

Atrial septal defect closure is a safe, simple and effective operation with excellent results. The ideal time for ASD closure is at the age of 4-5 years before the child goes to school. Spontaneous closure of the ASD is rare. ${ }^{9}$

In this series, most of the patients reported for surgery in 2nd and 3rd decades of life. This is due to the relative mild symptoms in the 1st decade of the life. All patients of ASD with Qp:Qs ratio of more than $2: 1$ should be considered for surgery. Age is not a contraindication. The presence of pulmonary vascular resistant, one half to one third of systemic resistant is considered as contraindicated for surgery. ${ }^{10}$

In these cases, $70 \%$ of patients were symptomatic at the time of operation where as in western population; most of the patients who undergo surgery are asymptomatic. Exertional dyspnea was the commonest presenting symptom where as easy fatigability could be elicited in most of the case after careful questioning. Sixteen percentage (16\%) patients presented with recurrent attacks of lower respiratory tract infections, most of them were below the age of 10 years.

These children were referred for investigations on detection of cardiac murmurs. On physical examination, all patients had ejection systolic

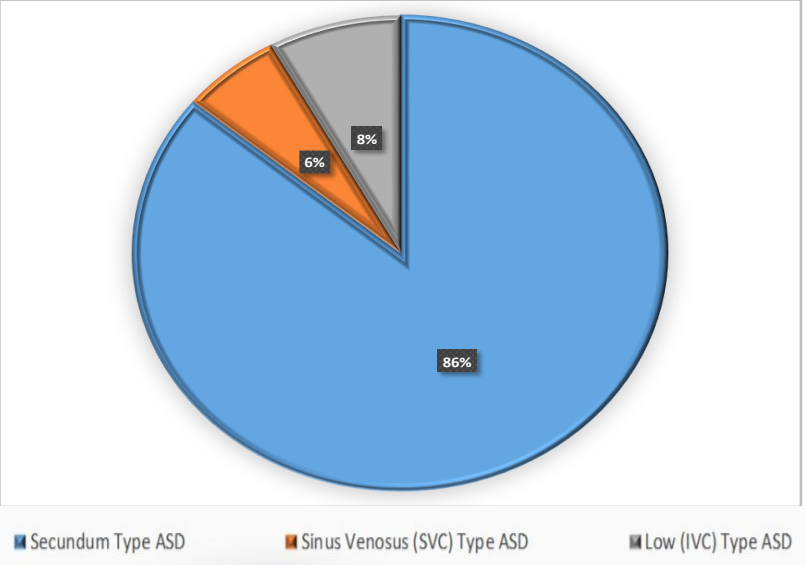

Fig 3: ASD Percentage

murmur at the pulmonary area with wide fixed split of S2. Most of the adults had parasternal heave and an accentuated P2 which indicates some degree of pulmonary hypertension. ${ }^{11-13}$

The sex distribution of 2.15:1(F: M), with female preponderance in our study is comparable to the $2: 1$ reported by many other series. ${ }^{14}$ Eighty-eight percent $(88 \%)$ of the patients belonged to NYHA functional class II, which is quite significant and indicates delay in reporting for surgery.

The radiologic combination of pulmonary plethora with marked dilation of the pulmonary trunk and its right branch and an inconspicuous ascending aorta is distinctive of ASD. The shadows of the pulmonary arteries and veins throughout both lungs become enlarged in cases of ASD with left to right shunt due to increased pulmonary blood flow. ${ }^{14}$

The central and peripheral segmental pulmonary arteries enlarge proportionately, maintaining normal ratio of less than $6: 1$. Fluroscopy is helpful in case of ASD with borderline roentgenographic findings by demonstrating increased intrinsic pulsations of the pulmonary arteries. ${ }^{15}$

There is almost always some variant of the rsR or RSR pattern (incomplete right bundle- branch block pattern) in lead V1. A partial or complete right bundle branch block pattern was seen in the tracing from $85 \%$ of the patients on the electrocardiogram in this study.

Right axis deviation was present in majority of cases. None of the patients had arrhythmia before operation. Two patients developed junctional rhythm and one patient developed atrial fibrillation post operatively. The mean QRS axis in the frontal plane was between 0 and 90 degrees in $17 \%$ of the patients and between 90 and 180 degrees in $83 \%$ of the patients.

Two D echocardiography visualizes the atrial septal 
defect and establishes its location and size as well as the physiologic consequences. In subcostal view, secondum ASD is characterized by an echofree space in the mid portion of the atrial septum. Mmode echocardiography demonstrates volume over load of the right side of the heart, characterized by increased right atrial and right ventricular dimensions and paradoxical ventricular septal motion.

Doppler echocardiography can reasonably determine the degree of left to right shunt across ASD by ratio of systemic blood flow (Qp/Qs). Blood flow across the pulmonary or aortic valves is determined by multiplying the VT1 (Velocity time integral) and valve area. ${ }^{15}$ Echocardiography was performed in all patients in our study. ${ }^{15}$

Majority of the patients were operated on the basis of clinical diagnosis with confirmation by echocardiography. Sinus venous ASD, partial anomalous pulmonary venous connection, pulmonary stenosis and mitral stenosis were also detected with echocardiography. Out of 100 patients with ASD in this series, 8 patients had associated pulmonary stenosis, 5 patients had PAPVC, one patient had mitral stenosis (Lutembacher's syndrome) and one patient had cortriatium. Therefore preoperative detailed assessment is crucial in all the patients and it determines the immediate and long term outcome after surgery.

\section{CONCLUSION}

Atrial septal defect surgery is safe and effective and gives excellent results when done while mild to moderate symptomatic. Small defect can be closed directly while large defect need pericardial patch closure.

\section{REFERENCES}

1. Moss AJ, Allen HD. Moss and Adams' heart disease in infants, children, and adolescents: including the fetus and young adult. New York: Lippincott Williams \& Wilkins; 2006. p.376.

2. Bedford DE. The anatomical types of atrial septal defect: their incidence and clinical diagnosis. Am J Cardiol. 1960;6:568-74.

DOI:10.1016/0002-9149(60)90258-7.

3. Daicoff GR, Brandenburg RO, Kirklin JW. Results of operation for atrial septal defect in patients forty-five years of age and older. Circulation. 1967;35(4 Suppl):143 -7. DOI:10.1161/01.cir.35.4s1.i-143.

4. Campbell M. Natural history of atrial septal defect. Br Heart J. 1970;32(6):820-6. DOI:10.1136/hrt.32.6.820;
PMID:5212356; PMCID:PMC487420.

5. Cassels DE, Bharati S, Lev M. The natural history of the ductus arteriosus in association with other congenital heart defects. Perspect Biol Med. 1975;18(4):541-72. DOI:10.1353/pbm.1975.0061; PMID:1165982.

6. Espada R, Whisennand HH, Mattox KL, Beall AC, Jr. Surgical management of penetrating injuries to the coronary arteries. Surgery. 1975;78(6):755-60. PMID:1188618.

7. Nojiri $T$, Shibata $T$, Hanji $Y$, Koike $K$. The natural history of neonates with congenital cardiovascular anomalies. Jpn Circ J. 1972;36(8):827-31. DOI: 10.1253/ jcj.36.827; PMID:4678662.

8. Odelola HA, Koza J. Characterization of Nigerian strains of West Nile virus by plaque formation. Acta Virol. 1975;19(6):489-92. PMID:1995.

9. Rahimtoola SH, Kirklin JW, Burchell HB. Atrial septal defect. Circulation. 1968;38(1 Suppl):2-12. DOI:10.1161/01.cir.38.1s5.v-2.

10. Sellers RD, Ferlic RM, Sterns LP, Lillehei CW. Secundum type atrial septal defects: early and late results of surgical repair using extracorporeal circulation in 275 patients. Surgery. 1966;59(1):155-64. PMID:5901449.

11. Shibuya M. The natural history of adult congenital heart disease. Jpn Circ J. 1972;36(8):832. PMID:4678663.

12. Murphy JG, Gersh BJ, McGoon MD, Mair DD, Porter CJ, Ilstrup DM, et al. Long-term outcome after surgical repair of isolated atrial septal defect: follow-up at 27 to 32 years. N Engl J Med. 1990;323(24):1645-50. DOI:10.1056/NEJM199012133232401; PMID:2233961.

13. Weiland AP, Walker WE. Physiologic principles and clinical sequelae of cardiopulmonary bypass. Heart Lung. 1986;15(1):34-9. PMID:3511011.

14. Anderson RH, Wilcox BR. Understanding cardiac anatomy: the prerequisite for optimal cardiac surgery. Ann Thorac Surg. 1995;59(6):1366-75. DOI:10.1016/0003-4975(95)00195-Q.

15. Erokhina IL, Selivanova GV, Vlasova TD, Emel'ianova OI. The DNA and protein content of atrial cardiomyocytes and the size and ultrastructure of the cardiomyocytes in children with congenital heart defects. Tsitologiia. 1995;37(1-2):101-8. PMID:7571014 